\title{
MANIPULAÇÕES POST-MORTEM DO CORPO HUMANO Implicações Arqueológicas e Antropológicas
}

\section{POST-MORTEM MANIPULATIONS OF THE HUMAN BODY Archaeological and Anthropological Implications}

Jennifer Kerner ${ }^{1}$

kerner.jennifer@gmail.com / https://orcid.org/0000-0003-4804-7441

\section{RESUMO}

Este trabalho é uma exploração das diferentes estratégias desenvolvidas pelas pessoas para responder ao problema do luto através das ações realizadas no cadáver. A manipulação post-mortem dos corpos regularmente fornece ao arqueólogo "sepulturas secundárias" e ossos "perturbados". Estas duas categorias são referidas com o termo genérico de "ossos na posição secundária" para expressar que os ossos não estão mais conectados e que a posição original do corpo não é mais legível. Estes depósitos são frequentemente subavaliados pelos arqueólogos porque são pouco compreendidos. Tais vestígios implicam uma gestão complexa e planejada do processo fúnebre e gestos / práticas / cerimônias em vários episódios. Eles são, portanto, valiosos para a compreensão de fenômenos sociais e crenças antigas. Esta tese propõe um esclarecimento dos conceitos relativos aos "ossos na posição secundária", bem como um aprimoramento da metodologia relacionada a esses depósitos específicos.

Palavras chaves: Etnoarqueologia; Processo funerário em múltiplas etapas; Métodos arqueológicos.

\footnotetext{
${ }^{1}$ Pesquisadora associada, UMR 7194, PRETROP, Musée de l'Homme, Paris, França.
}

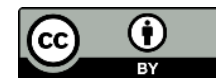




\begin{abstract}
Human remains resulting from sophisticated mortuary treatments represent a preferred information source about the organization of societies and about belief systems of ancient people. Secondary deposits, sacred artefacts made of humain bones or dismembered / scattered burials emerge as precious raw material in order to reconstruct gestures, practices and, finally, the symbolic discourse built around those dead who are selected to become particular protective entities, perhaps Ancestors. An ethnoarcheological study on multiplesteps funerals has been performed in order to improve methods of recognition of these peculiar remains on the archaeological field.
\end{abstract}

Keywords: Ethnoarchaeology; Multiple-steps funerals; Archaeological methods.

\title{
CONTEXTO DA PESQUISA
}

A morte dos outros é uma dor que as comunidades humanas tiveram que aprender a superar desde os primeiros tempos da humanidade. Diferentes estratégias foram postas em prática por pessoas que lidam com o problema da perda de seus entes. Dados antropológicos e arqueológicas destacam a pluralidade de métodos de tratamento dos restos humanos, (GODELIER, 2014; GUIART, 1979; DUDAY, 2009). Dessa diversidade de tratamentos nasce uma ampla gama de vestígios materiais que os arqueólogos enfrentam diariamente. Alguns desses restos são difíceis de interpretar. Este é o caso, por exemplo, de esqueletos incompletos devido a numerosas manipulações pós-deposicionais. Estas assembleias arqueológicas podem assumir a forma de "depósitos secundários", ossos "dispersos" ou ossos transformados em objetos. Todas estas formas, incluindo os ossos em desconexão anatômica, podem ser designadas sob o termo genérico de "ossos na posição secundária" ou "depósito secundário". Esse último não deve ser confundido com a sepultura secundária do qual ele difere.

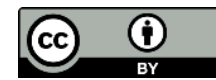


Com efeito, dizer que um osso está "na posição secundária" é uma simples observação da desconexão anatômica, ao passo que falar de uma "sepultura secundária" já é uma interpretação do fato arqueológico em relação ao gesto funerário, (BOULESTIN \& DUDAY, 2005). "Sepultura secundária" é um termo que se refere ao movimento intencional e respeitoso dos ossos de uma pessoa falecida. Também é muito importante notar que a sepultura secundária pode ser composta de ossos com conexão anatômica parcial - se o deslocamento do corppo é feito antes do final do processo de decomposição - ou quase total se ocorrer uma mumificação natural do corpo, (DUDAY \& SELLIER, 1990).

Esta tese propõe uma exploração das diferentes estratégias adotadas pelas populações que se veem diante do cadáver do ente, desde o atendimento tanatopratico até ao funeral em vários tempos ou a criação de relíquias que são susceptíveis de produzir "ossos na posição secundária". Para isso, populações antigas e atuais foram estudadas partindo dos mesmos princípios. Essa exploração nos permitiu propor uma leitura antropológica de alguns vestígios arqueológicos funerários complexos que têm sido inexplorados, graças a ajustes metodológicos que contam com análise estatística e análise do espaço arqueológico extenso. 


\section{QUAIS VESTÍGIOS ESTÃO ENVOLVIDOS? (RE)DEFINIÇÃO DE CONCEITOS}

As assembleias arqueológicas compostas de ossos humanos desconectados e/ou deslocados sempre foram um enigma para os arqueólogos funerários. Muitas menções aos obstáculos metodológicos apresentados em seu estudo foram feitas na literatura francesa e anglo-saxônica, (WHAL, 2008; DUDAY et al. 1990; DUDAY \& GUILLON, 2006; DUDAY, 2009). Esta tese pretendeu preencher essa lacuna metodológica para poder interpretar esses vestígios. O estudo inclui, portanto, todos os tipos de depósitos ósseos na posição secundária, bem como os depósitos primários que sofreram manipulações pré-deposicionais que desestruturaram a ordem anatômica normal, (isto é, cadáveres submetidos a preparação intensiva e seu depósito no estado "fresco" na forma de corpos desmembrados por exemplo). Estes vários tipos de depósitos correspondem a várias assembleias arqueológicas.

Elas são frequentemente designadas em arqueologia pelos seguintes termos: reduções, (DUDAY \& SELLIER, 1990), depósitos secundários, (PARKER PEARSON, 1999:50 ; LECELRC, 1990:16), estrutura de decomposição (essas estruturas são chamadas em francês "pourrissoir", propomos chamá-los em português pelo neologismo de "putrefatório", (KERNER et al. 2019)), sepultura temporária, áreas de tratamento de corpos em vários estágios de decomposição, troféus, relíquias ancestrais ou religiosas, objetos seculares ou sagrados feitos a partir de ossos humanos.

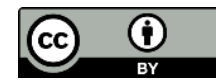


Clio Arqueológica 2021, V36N1, p.77-89, KERNER

DOI: 10.51359/2448-2331.2021.250745

\begin{tabular}{|c|c|c|c|}
\hline $\begin{array}{c}\text { Tipos de } \\
\text { assembleias } \\
\text { arqueológicas }\end{array}$ & Lugares & Peças osteológicas presentes & objetos mortuários \\
\hline $\begin{array}{l}\text { sepultura } \\
\text { secundária }\end{array}$ & $\begin{array}{c}\text { cemitério / } \\
\text { lugares selvagens }\end{array}$ & $\begin{array}{l}\text { ossos grandes principalmente / } \\
\text { todos os ossos podem estar } \\
\text { presentes }\end{array}$ & $\begin{array}{l}\text { bens pessoais do } \\
\text { morto / bens } \\
\text { oferecidos aos mortos }\end{array}$ \\
\hline relíquia & $\begin{array}{l}\text { habitação / lugar } \\
\text { religioso }\end{array}$ & $\begin{array}{l}\text { todos os ossos podem estar } \\
\text { presentes / crânios } \\
\text { principalmente }\end{array}$ & $\begin{array}{l}\text { bens oferecidos aos } \\
\text { mortos: objetos preciosos } \\
\text { e / ou ofertas regulares de } \\
\text { alimentos }\end{array}$ \\
\hline ossuário & $\begin{array}{l}\text { perto de lugares } \\
\text { religiosos / perto } \\
\text { de putrefatório }\end{array}$ & ossos grandes principalmente & ausência de objetos \\
\hline putrefatório & $\begin{array}{l}\text { perto de lugares } \\
\text { religiosos / perto } \\
\text { de ossuário }\end{array}$ & $\begin{array}{l}\text { ossos pequenos principalmente / } \\
\text { ossos mantidos por articulações } \\
\text { lábeis / ossos fragmentados }\end{array}$ & bens pessoais do morto \\
\hline redução & cemitério & $\begin{array}{c}\text { todos os ossos podem estar } \\
\text { presentes }\end{array}$ & $\begin{array}{l}\text { bens pessoais do morto / } \\
\text { bens oferecidos aos } \\
\text { mortos }\end{array}$ \\
\hline
\end{tabular}

Figura 1. Tabela sintética de categorizações de assembleias arqueológicas apresentando os ossos na posição secundária com seus critérios de identificação nos sítios arqueológicos.

Arqueólogos frequentemente descrevem estruturas usando essas palavras, como se a mera emissão da palavra fosse suficiente para explicar a realidade antropológica por trás do vestígio. No entanto, a investigação etnológica que conduzimos durante esta tese permitiu demonstrar que depósitos ósseos humanos com formas idênticas poderiam ter significados muito diferentes ou mesmo opostos. A partir de uma extensa revisão da literatura inglesa e francesa, procurou-se identificar as características materiais que justificam o uso dessas diferentes palavras na literatura 
acadêmica para explicá-las e refiná-las. Essas sínteses e redefinições são ilustradas por casos arqueológicos e etnológicos precisos.

\section{DADOS EMPREGADOS}

A eficácia dessas novas categorias foi então testada durante a análise de campo em sítio escavado por nós e através do estudo de arquivos de escavações já realizadas, mas não publicadas. Entre os dados inéditos estão o sítio neolítico de Ding Si Shan, (China), escavado por nós, os níveis epipaleolíticos da caverna de Mas d'Azil, (França) e o sítio proto-histórico de La Digue à Marsal, (França).

Quanto aos estudos de arquivos de escavação, esses dados vêm de sítios selecionados nos cinco continentes, do Paleolítico Médio à Era Moderna. Os sítios arqueológicos foram escolhidos de acordo com os seguintes critérios: 1), a precisão dos dados disponíveis que permitia uma reavaliação das conclusões interpretativas através de uma reanálise das assembleias arqueológicas, 2), os locais que fossem representativos de uma diversidade de práticas mortuárias o mais vasta possível.

Também compilamos um corpo de dados etnológicos que informam o fenômeno funerário em vários episódios, relíquias, troféus ou objetos em ossos humanos. Sessenta e oito populações atuais e sub-atuais foram abordadas, (Figura 2). 


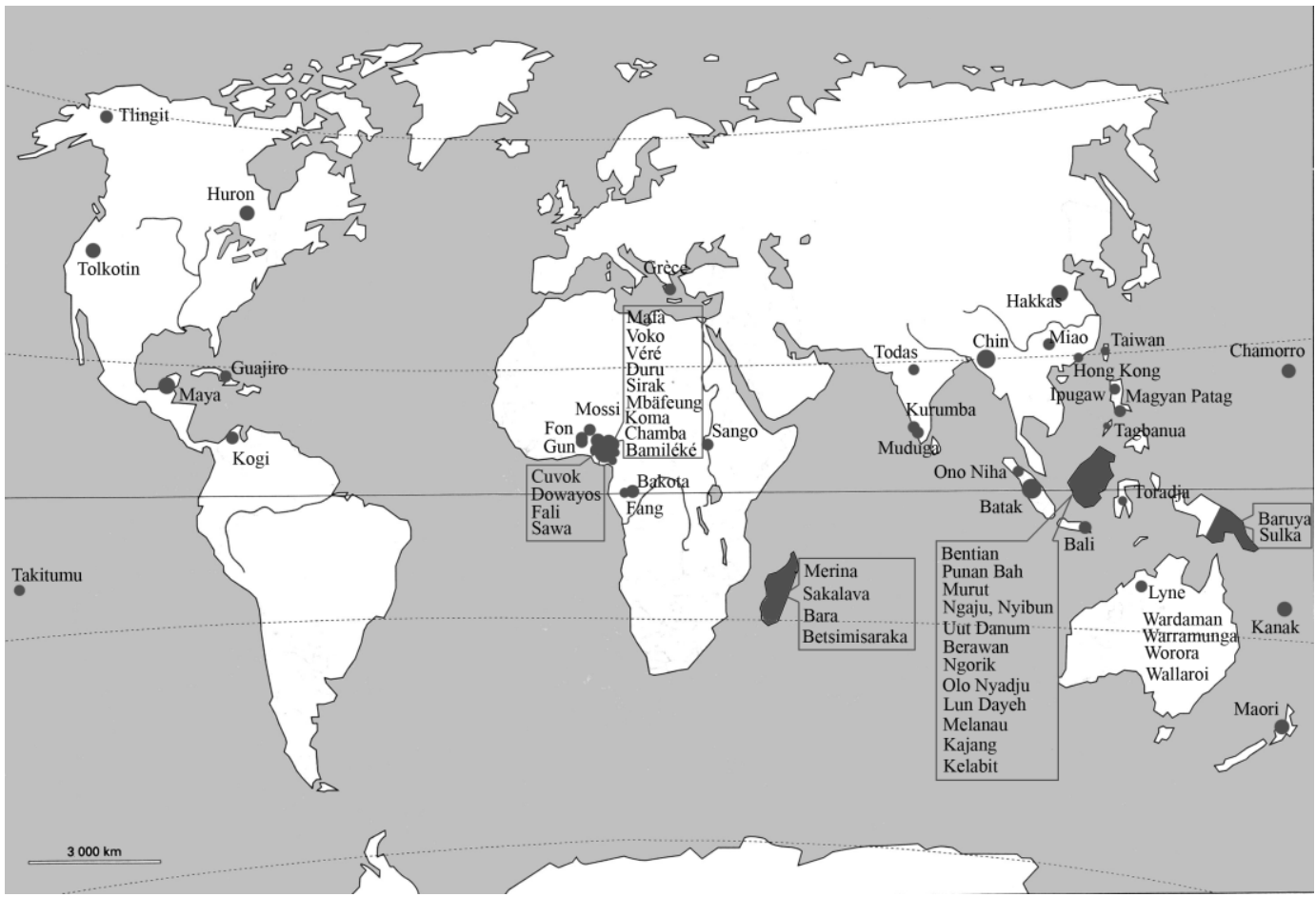

Figura 2. Populações atuais e sub-atuais estudadas neste estudo.

\section{METODOLOGIA}

É importante propor uma abordagem global sobre os eventos mortuários através do prisma da antropologia, antropologia física e arqueologia. Portanto, utilizamos os métodos da tanatoarqueologia, (DUDAY et al., 1990) que permitem a análise dos contextos mortuários e a determinação dos perfis biológicos dos indivíduos. 
Às vezes a transformação do cadáver é tão intensa que resulta na modelagem do que pode ser chamado de "corpo-objeto". Alguns ossos também podem se tornar artefatos. Para entender essas modificações antropogênicas voluntárias, é necessário o uso de análise tecno-funcional, (Figura 3).

\section{QUESTÕES ANTROPOLÓGICAS E EVIDENCIAS ARQUEOLÓGICAS}

A reconstrução de "chaines opératoires" funerárias a partir da análise de restos sepulcrais foi testada e aprovada por décadas. Mas uma vez que os gestos são reconstituídos, um grande obstáculo persiste: compreender o significado antropológico das ações realizadas ao redor do cadáver.

O acesso ao "pensamento subjacente ao gesto", (P. Chambon, em BOULESTIN \& DUDAY, 2005:33) é um dos objetivos mais estimulantes e perigosos para o arqueólogo funerário. É até mesmo um desafio para o pesquisador que é obrigado a fazer uma "arqueologia do sentimento", (LECLERC, 1990:18), uma antropologia arqueológica do sensível, apenas a partir da materialidade dos fatos. Para este fim, a etnologia tem sido freqüentemente invocada pelos arqueólogos... Os quais se viram confrontados com armadilhas metodológicas que são difíceis de serem contornadas, (TESTAR, 2006). 


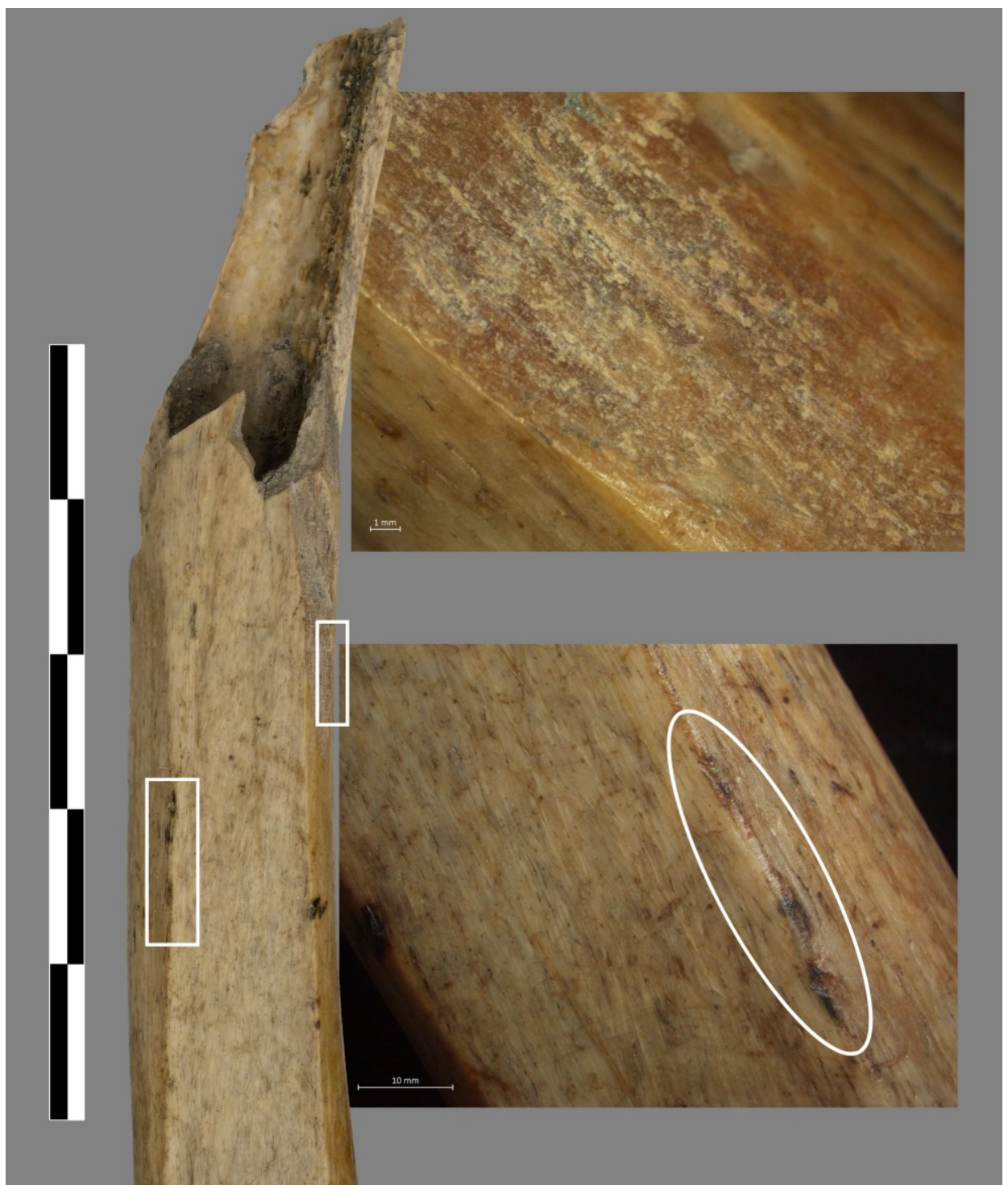

Figura 3. Estudo tecno-funcional realizado em um fêmur humano de La Digue à Marsal (França). Fomos capazes de propor um uso como patins de trenó.

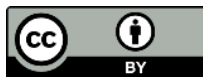




\section{CONSIDERAÇÕES FINAIS: POR UMA NOVA ETNOARQUEOLOGIA DOS FATOS MORTUÁRIOS}

No Brasil, os pesquisadores têm a oportunidade de iluminar os vestígios do passado observando os chamados descendentes "diretos" das populações arqueológicas analisadas, (PROUS, 1992:51). Mas essa configuração é rara em outras partes do mundo. Então, como se pode ir além do quadro razoável da aplicação dessa etnoarqueologia que se limita à observações de descendentes "diretos"? Como ir além deste arcabouço, evitando o obstáculo de uma pseudo-etnoarqueologia que procede por um simples comparatismo analógico? Como encontrar, entre os "invariantes" da antropologia da morte, (GODELIER, 2014), pistas que permitam compreender as estratégias mortuárias do passado sem perder de vista as especificidades culturais de cada população?

Propomos um protocolo para a interpretação dos restos osteológicos em desconexão anatômica através de uma abordagem etno-arqueológica quantitativa e probabilística. Quantitativa porque é baseada em dados coletados de maneira ampla para fornecer um panorama "completo" das possibilidades de ações complexas sobre o cadáver. Probabilística porque esses dados são processados estatisticamente para levantar as hipóteses mais plausíveis. Para evitar realizar a mera enumeração das prováveis hipóteses interpretativas sobre um depósito arqueológico, propomos confrontar essas diferentes hipóteses com os dados materiais e testá-los com uma grade de conhecimentos antropológicos. Deste modo, podemos fazer emergir a 
hipótese mais provável de acordo com o contexto arqueológico, não ignorando a cultura da qual os restos são provenientes.

Esta exploração passa, assim, pela observação dos seguintes dados: os restos materiais que resultam dos gestos mortuários, o reconhecimento das práticas executadas e uma análise dos discursos associados a determinadas práticas mortuárias específicas nas sociedades para as quais esses dados são acessíveis, (testemunhos orais ou fontes escritas, diretas ou indiretas). Esta abordagem destaca diferentes critérios de identificação, discriminando variáveis que podem ser distinguidas no campo arqueológico. Esse método leva à criação de grades para leitura e interpretação de vestígios arqueológicos.

Tais quadros de análise foram estabelecidos durante nossa pesquisa de doutorado para cenotáfios e processos funerários em múltiplas etapas. Posteriormente, eles foram testados em assembleias arqueológicas com resultados satisfatórios. É óbvio que essas ferramentas devem ser manipuladas fazendo-se a ligação constante com os outros dados conhecidos sobre a cultura à qual os depósitos funerários estão ligados: o arqueólogo nunca deve perder de vista a especificidade de seu campo e a estrutura crono-cultural de seu estudo. Nossas grades de leitura não pretendem substituir o trabalho de cada especialista das diferentes culturas, propondo um léxico interpretativo universal. Pelo contrário, constituem ferramentas adicionais para apoiar a sua reflexão, que deve estar ancorada em um conhecimento profundo da população arqueológica estudada para ser eficaz.

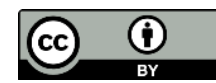




\section{REFERÊNCIAS BIBLIOGRÁFICAS}

BOULESTIN, B. \& DUDAY, H. 2005. "Ethnologie et archéologie de la mort : de l'illusion des références à l'emploi d'un vocabulaire". In C. Mordant \& G. Depierre (dir.). Les pratiques funéraires à l'âge du Bronze en France, actes de la table ronde de Sens-enBourgogne, (Yonne), Paris, CTHS, (Documents préhistoriques, 19); Sens-en-Bourgogne, société archéologique de Sens, 17-35.

DUDAY, H. 2009. The Archaeology of the Dead: Lectures in Archaeothanatology. Oxford: Oxbow Books.

DUDAY, H.; COURTAUD P.; CRUBEZY E., SELLIER P. \& TILLIER A.-M. 1990. "L'Anthropologie « de terrain »: reconnaissance et interprétation des gestes funéraires". Bulletins et Mémoires de la Société d'anthropologie de Paris vol. 2(3), 29-49.

DUDAY H. \& SELLIER P., 1990. "L'archéologie des gestes funéraires et la taphonomie." Les Nouvelles de l'Archéologie 40, 12-14.

DUDAY H. \& GUILLON M., 2006. "Understanding the circumstances of decomposition when the body is skeletonized" In A. Schmitt, E. Cunha \& J. Pinheuri (Dirs.). Forensic Anthropology and Medecine : Complementary Sciences From Recovery to Cause of Death. Totowa NJ: Humana Press Inc, 117-157.

GODELIER, M. (dir.) 2014. La mort et ses au-delà[s]. Paris: CNRS.

GUIART, J. 1979. Les hommes et la mort. Rituels funéraires à travers le monde. Paris: Le Sycomore, Objets et Mondes, la revue du Musée de l'Homme.

KERNER, J. 2014. "Segregation of Mortuary Spaces within the Context of Multiple-Steps Funerals: an Ethnoarchaeological Approach Applied to Neolithic Pouilly (France)". Archaeological Review of Cambridge vol. 30(1), 134-142.

KERNER, J. 2018. Manipulations post-mortem du corps humains: implications archéologiques et anthropologiques. Leiden: SideStone Press. 
KERNER, J.; BOEDA, E.; CLEMENTE CONTE, I. J., 2019. Toca do Pedrinho: um excepcional local de tratamento mortuário na serra da capivara, Nordeste do Brasil, (PI). Relatório de escavação.

LECLERC, J. 1990. "La notion de sépulture". Bulletins et Mémoires de la Société d'anthropologie de Paris vol. 2 (3), 13-18.

PARKER PEARSON, M. 1999. The Archaeology of Death and Burial. Stroud: Sutton. PROUS, A. 1992. Arquéologia Brasileira. Brasília: Editora Universidade de Brasília.

TESTART, A. 2006. "Comment concevoir une collaboration entre anthropologie sociale et archéologie ? À quel prix ? Et pourquoi ?”. Bulletin de la Société préhistorique française vol. 103 (2), 385-395.

WHAL, J. 2008. "Investigations on Pre-roman and roman cremation remains from Southwestern Germany : results, Potentiality and Limits" In C. W. Schmidt \& S. A. Symes (Eds.). The Analysis of Burned Human Remains. London: Academic Press, 145-161. 